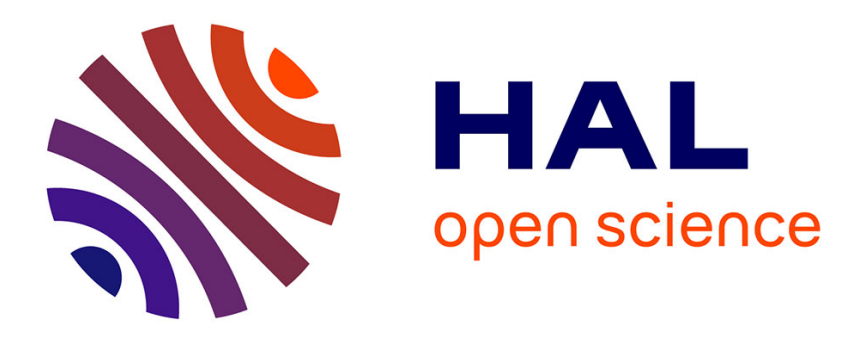

\title{
Regional identification of mechanical properties in arteries
}

Stéphane Avril, Matthew R. Bersi, Chiara Bellini, Katia Genovese, Jay D. Humphrey

\section{- To cite this version:}

Stéphane Avril, Matthew R. Bersi, Chiara Bellini, Katia Genovese, Jay D. Humphrey. Regional identification of mechanical properties in arteries. Computer Methods in Biomechanics and Biomedical Engineering, 2015, 18 (1), pp.1874-1875. 10.1080/10255842.2015.1070577 . hal-01273081

\section{HAL Id: hal-01273081 \\ https://hal.science/hal-01273081}

Submitted on 12 Feb 2016

HAL is a multi-disciplinary open access archive for the deposit and dissemination of scientific research documents, whether they are published or not. The documents may come from teaching and research institutions in France or abroad, or from public or private research centers.
L'archive ouverte pluridisciplinaire HAL, est destinée au dépôt et à la diffusion de documents scientifiques de niveau recherche, publiés ou non, émanant des établissements d'enseignement et de recherche français ou étrangers, des laboratoires publics ou privés. 


\title{
Regional identification of mechanical properties in arteries
}

\author{
S. Avril ${ }^{\mathrm{a} *}$, M.R. Bersi ${ }^{\mathrm{b}}$, C. Bellini ${ }^{\mathrm{b}}$, K. Genovese ${ }^{\mathrm{c}}$ and J.D. Humphrey ${ }^{\mathrm{b}}$ \\ ${ }^{a}$ Ecole Nationale Supérieure des Mines de Saint-Etienne, Saint Etienne, France $;{ }^{b}$ Department of Biomedical \\ Engineering, Yale University, New Haven, CT, USA; ${ }^{c}$ Dipartimento di Ingegneria e Fisica dell'Ambiente, Università \\ degli Studi della Basilicata, Potenza, Italy
}

Keywords: Arteries, mechanobiology, identification, hyperelasticity, mechanical behavior.

\section{Introduction}

Aortic aneurysms are often characterized by localized changes in aortic wall composition and structure that result from the degradation of elastin, loss of smooth muscle cell function, and remodeling of collagen. Correlations between wall composition and local mechanical properties can potentially provide insight into conditions that render a vessel susceptible to failure. Previous work has shown that chronic angiotensin-II infusion in $\mathrm{ApoE}^{-/-}$mice often results in dissecting aneurysms (Bersi et al. 2012). The objective of this work is to establish a new protocol able to characterize in vitro the local mechanical properties of arteries on the murine model.

\section{Methods}

The constitutive behaviour of the aorta is modeled using a microstructurally motivated constrained mixture bilayer model (Bellini et al. 2014). The media is modeled as a hyperelastic membrane having a strain energy function per unit mass of the form: $W^{i}=\phi^{e} W^{\theta}+\phi^{m} W^{m}$ where $\phi^{e}$ is the local mass fraction of elastin for each position (averaged over the thickness) and $\phi^{m}$ is the total mass fraction of collagen fibers and smooth muscle cells in the media for each position. In particular, relations for the elastin and smooth muscle are:

$$
W^{\theta}=\frac{c^{\theta}}{2}\left[\left(\left[\lambda_{\varepsilon 1}^{m}\right]^{2}+\left[\lambda_{\varepsilon 2}^{m}\right]^{2}+\left[\frac{1}{\lambda_{e 1}^{m} \lambda_{e 2}^{m}}\right]^{2}\right)-3\right]
$$

$W^{m}=\frac{c^{m}}{4 \kappa^{m}}\left[\left[e^{x^{m}\left[\left[x_{r}^{m}\right]^{2}-\left.1\right|_{+} ^{2}\right.}-1\right]+\alpha^{m}\left[e^{x^{m}\left[\left[k_{m}^{m}\right]^{2}-\left.1\right|_{-} ^{2}\right.}-1\right]\right]$

where $\mathrm{c}^{\varepsilon}, \mathrm{c}^{\mathrm{m}}, \mathrm{K}^{\mathrm{m}}$ and $\alpha^{\mathrm{m}}$ are material parameters, $\alpha^{\mathrm{m}}$ accounts for the lower contribution of fibers to compression than to tension. Moreover, $\lambda_{i 1}^{m}$ and $\lambda_{\theta 2}^{m}$ are elastic stretches of the elastin in the media. They are defined such as: $\lambda_{\varepsilon 1}^{m}=\lambda_{1}^{m} G^{E 1}, \lambda_{\varepsilon 2}^{m}=\lambda_{2}^{m} G^{\varepsilon 2}$, where $G^{\varepsilon 1}$ and $G^{\varepsilon 2}$ are the circumferential and axial deposition stretches, respectively, for elastin. Finally, $\lambda_{c}^{m}$ is the elastic stretch of the collagen fibers and smooth muscle cells in the media, defined as: $\lambda_{c}^{m}=\lambda_{1}^{m} G^{m}$, where $G^{m}$ is the average deposition stretch of collagen and smooth muscle cells in the media.

The adventitia was similarly modeled as hyperelastic membrane having a strain energy function per unit mass of the form: $W^{0}=0.05 \phi^{\oplus} W^{e 0}+\phi^{c} W^{e}+\phi^{\alpha} W^{\alpha}$ where $0.05 \phi^{\theta} W^{e 0}$ accounts for the small, but nonnegligible, response of elastin in the adventitia. It is assumed that the mass fraction of elastin is $5 \%$ that of the media. Additionally, $\phi^{e}$ is the local mass fraction of diagonal collagen fibers (oriented respectively and on average at an angle $\mp \beta$ towards the axial direction), $\phi^{\alpha}$ is the local mass fraction of axial collagen fibers, $W^{e}$ is the local strain energy of diagonal collagen fibers, and $W^{\widetilde{a}}$ is the local strain energy of the axial fibers. Hence,

$W^{E \theta}=\frac{\mathrm{c}^{\theta}}{2}\left[\operatorname{tr}\left(\underline{C_{2 D}^{G \theta}}\right)+\frac{1}{\operatorname{det}\left(\underline{C_{2 D}^{a \theta}}\right)}-3\right]$

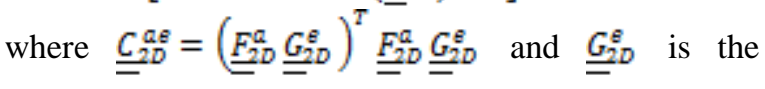
deposition stretch tensor of elastin. Finally,

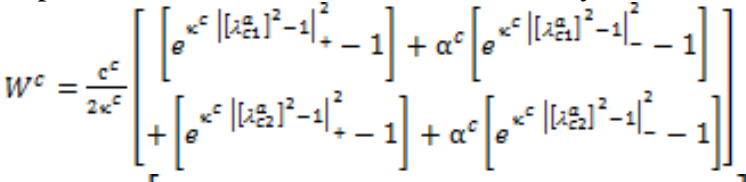

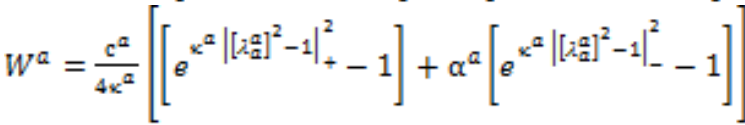

where $\mathrm{c}^{\sigma}, \mathrm{k}^{\varepsilon}, \mathrm{c}^{\alpha}, \mathrm{k}^{\alpha}, \alpha^{\varepsilon}$ and $\alpha^{\alpha}$ are parameters to be determined and $\alpha^{\sigma}$ and $\alpha^{\alpha}$ account for the lower contribution of fibers to compression than to tension. Note, too, that $\lambda_{a}^{a}$ is the average elastic stretch of axial collagen fibers in the adventitia. 


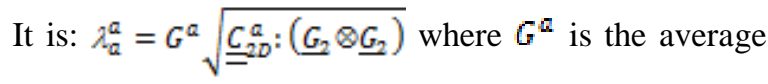
deposition stretch of axial collagen fibers in the adventitia. Also, $\underline{C_{2 D}^{a}}=\left(\underline{F_{2 D}^{a}}\right)^{T} \underline{F_{2 D}^{a}}$. $\hat{\lambda}_{\tau 1}^{a}$ and $\lambda_{c 2}^{a}$ are the average elastic stretches of diagonal collagen fibers in the adventitia ( 1 and 2 represent 2 symmetric directions in the reference configuration). They are defined as: $\lambda_{\mathrm{ci}}^{a}=G^{c} \sqrt{\frac{C_{2 D^{n}}^{a}\left(A_{i} \otimes A_{i}\right)}{\underline{A_{i}}}}$ where $G^{c}$ is the average deposition stretch of diagonal collagen fibers in the adventitia and:

$\underline{A}_{\mathrm{i}}=\cos (\beta) \underline{G_{1}}-(-1)^{\mathrm{i}} \sin (\beta) \underline{G_{2}}$

Identification. Local mechanical properties are quantified in site-specific aortic segments (Figure 1) by combining, for the first time, a computercontrolled biaxial testing system (cyclic pressure loading at different axial stretches (Gleason et al. 2004), a panoramic-Digital-Image-Correlation measurement system (Genovese et al. 2013), an Optical Coherence Tomographic scanning system, and a regional inverse analysis.

The regional inverse analysis is based on the virtual fields method (Avril et al. 2010) applied at the different stages of the biaxial loading protocol. Eventually, the identified regional mechanical properties are compared to constituent area fractions obtained using quantitative histological analyses.

\section{Results and discussion}

Two mice aortas were tested: an untreated control aorta and an ANG-II induced dissecting aneurysm. The control aorta showed a gentle cylindrical shape whereas the dissecting aneurysm showed a complex geometry and extensive intramural thrombosis (Figure 1). The average material properties identified on the control aorta showed a good agreement with a traditional identification approach.

When looking at the local properties reported in Tab. 1, important regional variations were identified. These regional variations are related to heterogeneities in the composition of the tissue. Combining such findings with advances in growth and remodeling simulations promises to improve our ability to predict rupture risk in aortic aneurysms.

\section{Conclusions}

Results highlight the necessity to better understand the mechanobiological processes governing the balance between extracellular matrix production and degradation in health and disease, as ultimately it is alterations to this homeostatic balance that can render vessels susceptible to vascular disorders.

\section{Acknowledgements}

The authors are grateful to the region Rhône-Alpes for funding Stéphane Avril's visit to Yale University, to the NIH for grants R01 HL105297, R21 HL107768, and U01 HL116323 and to the ERC for grant ERC-2014-CoG BIOLOCHANICS.

\section{References}

Avril S, Badel P, Duprey A. 2010. Anisotropic and hyperelastic identification of in vitro human arteries from full-field measurements $\mathrm{J}$ Biomech. 43:2978-85.

Bellini C, Ferruzzi J, Roccabianca S, Di Martino ES, Humphrey JD. 2014. A microstructurally motivated model of arterial wall mechanics with mechanobiological implications. Ann Biomed Eng. 42(3):488-502.

Bersi M, Collins MJ, Wilson E, Humphrey JD. 2012. Disparate changes in the mechanical properties of murine carotid arteries and aorta in response to chronic infusion of angiotensin-II. Int J Adv Eng Sci Appl Math. 4:228-240.

Genovese K, Lee YU, Lee AY, Humphrey JD. 2013. An improved panoramic digital image correlation method for vascular strain analysis and material characterization. J Mech Behav Biomed Mater, 27:132-142.

Gleason RL, Gray SP, Wilson E, Humphrey JD. 2004. A multiaxial computer-controlled organ culture and biomechanical device for mouse carotid arteries. J Biomech Eng. 126(6):787-795.

Tab 1 Material parameters identified in the 5 circumferential regions.

\begin{tabular}{|c|c|c|c|c|c|}
\hline & 1 & 2 & 3 & 4 & 5 \\
\hline $\mathrm{c}^{\mathbb{E}}(\mathrm{kPa})$ & 47.5 & 77.2 & 61.3 & 0.0 & 81.8 \\
\hline $\mathrm{c}^{\mathrm{m}}(\mathrm{kPa})$ & 431.6 & 629.1 & 398.5 & 0.0 & 0.0 \\
\hline $\mathrm{c}^{\mathbb{a}}(\mathrm{kPa})$ & 327.7 & 43.2 & 228.7 & 16.8 & 0.0 \\
\hline $\mathrm{c}^{\mathbb{C}}(\mathrm{kPa})$ & 107.7 & 204.8 & 78.7 & 498.5 & 143.4 \\
\hline
\end{tabular}

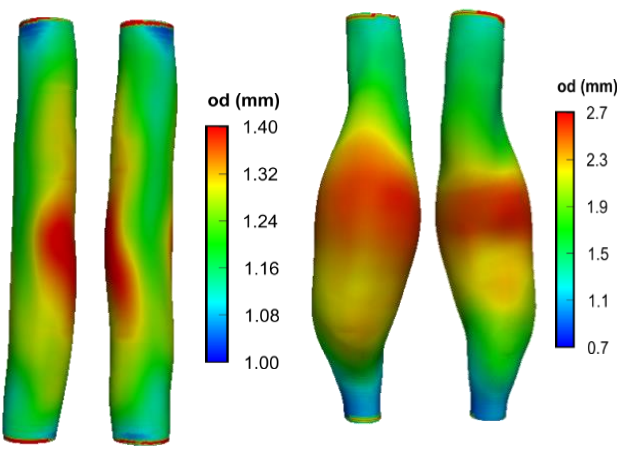

Figure 1 Quantitative reconstruction of local radii colormaps of the control artery (left) and a dissecting aneurysm (right) during the tension inflation tests. 